\title{
Se eu fosse uma espectadora portuguesa
}

\author{
Martina Mašlárová
}

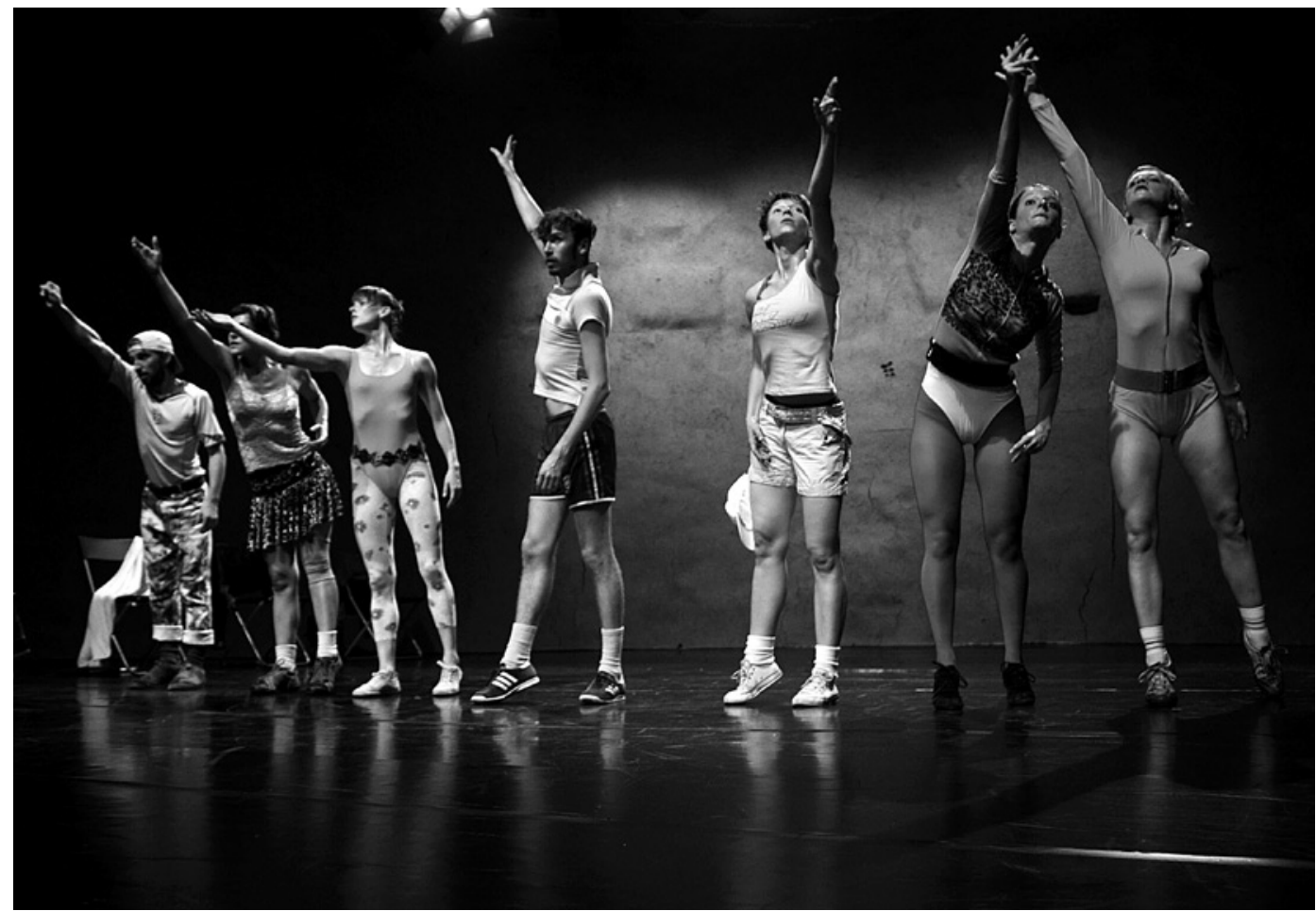

Much More than Nothing, group ME-SA, 2012 (Peter Šavel, Stano Dobák_Jaro Viňarský, Andrea Opavská, Martina Hajdyla Lacová, Peter Šavel, Tereza Ondrová, Karolina Hejnová, Lucia Kašiarová) fot. Natália Zajačiková.

Escrever sobre teatro para uma revista estrangeira é sempre uma tarefa complicada. Especialmente nestas condições: o meu conhecimento sobre Portugal e sobre o teatro português é, para usar um eufemismo, escasso. Não sei, portanto, o que poderá interessar ao leitor de uma revista portuguesa saber sobre o teatro no meu país, a Eslováquia. A pensar nisto mesmo, lembrei-me de um espectáculo britânico a que assisti em Julho passado no festival internacional de escolas de teatro Istropolitana. 0 espectáculo chamava-se Grey Matters e era sobre personagens que tentavam entrar nas mentes umas das outras. Quase como um refrão, diziam amiúde: "Se eu tivesse a mente de $\mathrm{X}$, eu...". Tentei, assim, fazer o mesmo. Como seria se eu entrasse na mente de um leitor português? Se fosse uma leitora portuguesa, o que teria eu gostado mais no teatro eslovaco na última temporada? E o que gostaria eu de ir ver na Eslováquia? Decidi jogar este jogo comigo mesma: que espectadora seria eu?

Estaria farta de ver remontagens de peças de Shakespeare, Ibsen ou Tchekov pela enésima vez e estaria eu curiosa por descobrir teatro novo, autêntico, baseado em novas dramaturgias? Se fosse esse o caso visitaria, seguramente, a Eslováquia em Maio, quando o Instituto Eslovaco de Teatro organiza o festival Nová Dráma (Novo Drama). Neste evento, que decorre em Bratislava desde há oito anos, os espectáculos partem ora de textos dramáticos de jovens autores eslovacos (na sua maioria inéditos) ou operam em gramáticas teatrais não dependentes de texto, tal como o vencedor da edição deste ano, a vídeo-performance Pokus (Tentativa). Neste caso, a maior parte do espectáculo consiste num documentário sobre um dos mais influentes artistas da cena teatral alternativa e independente na Eslováquia, 0 encenador Blaho Uhlár. É uma confissão frontal, rude e violenta, mas simultaneamente poética, sobre um homem frustrado com as condições de trabalho - depauperadas - em que um artista independente tem que criar.

De maneira similar, o projecto Some Disordered Interior Geometries (Algumas geometrias interiores desordenadas) da jovem (e já famosa) Sláva Daubnerová e da sua companhia P.A.T., também não parte de nenhum texto dramático, contendo somente fragmentos do conto de Heiner Müller, Die Todesanzeige (O anúncio de morte), obedecendo a tradução desses excertos às necessidades
Martina Mašlárová (1988) frequenta 0 mestrado em Teoria Teatral e Crítica na Faculdade de Teatro da Academia de Artes Performativas, em Bratislava. É membro da IATC/AICT e escreve regularmente para várias revistas eslovacas. 

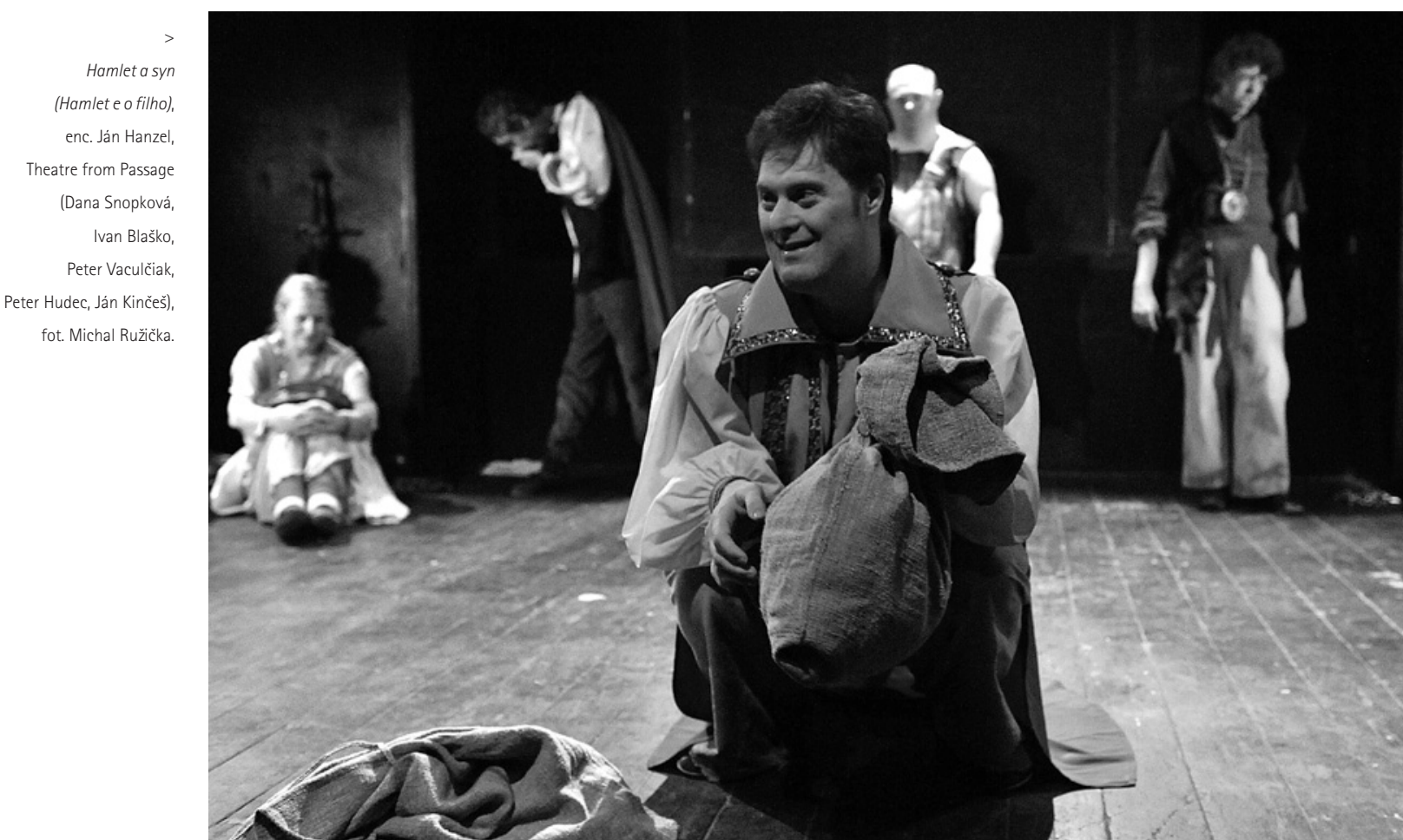

fot. Michal Ružička.

fot. Michal Ruzicka.

dramatúrgicas de Daubnerová. Num espectáculo que combinava teatro-físico, dança, vídeo-arte e concerto musical, explorava-se o tema do luto e da perda do amor interpretado pela própria Daubnerová e pelo seu companheiro Pavel Graus.

Mas outros espectáculos apresentados no Nová Dráma podem ser baseados em textos de autores - muito jovens, tais como Havaj (Havai) de Michaela Zakut'anská, fascinante pelo dialecto falado pelos protagonistas que vêm de Havaj - a pequena aldeia Medzilaborce, que se pensa ser o local de nascimento de Andy Warhol. Ou a peça Kukura, de Martin Čičfvák, apresentada no teatro Arena, onde se apresenta uma "personagem" real, Juraj Kukura, o director desse mesmo teatro Arena, interpretado por quarto actores diferentes em simultâneo. As suas opiniões são um diagnóstico à cultura eslovaca, identificando doenças como os reality shows estupidificantes, séries televisivas vulgares, etc.

No Nová Dráma, para além dos espectáculos que fazem parte da programação principal, há também uma competição para textos dramáticos de autores muito jovens. Os três vencedores são alvo de uma leitura pública durante o festival, num evento intitulado Triathlon. Mas os espectáculos aqui apresentados também podem ser de autores estrangeiros contemporâneos. Este ano foram apresentados Taká fajn baba ako ty (Uma rapariga simpática como tu), de Ingmar Villqist, November (Novembro), de David Mamet, ou, da jovem autora polaca Dorota Maslowska Dvaja úbohi Rumuni hovoriaci po pol'sky (Dois pobres:

Romenos que falam polaco). Na secção "Focus", onde se dá destaque a um pais diferente em cada ano, foram, em 2012, apresentados espectáculos de criadores polacos, tais como o grupo Ad spectatores com a sua aventura experimental, onde os espectadores, de olhos vendados, eram conduzidos a um local para "sobreviver" ao espectáculo 9 Rekonštrukcia (Reconstrução 9) - tornando-se o espectador um dos cadáveres assassinados numa cave.
Alguns dos espectáculos apresentados no Nová Dráma circulam depois pela Eslováquia, ao abrigo de uma iniciativa chamada Enter. Mas, se por alguma razão o espectador não puder acompanhar este festival (nem as datas integradas no Enter), ainda terá oportunidade de ver alguns destes espectáculos. Por exemplo, durante o Touches and Connections, em Martin, um dos mais importantes centros históricos de arte e cultura, no final de Junho.

Se eu fosse uma espectadora estrangeira e quisesse conhecer rapidamente a diversidade do teatro na Eslováquia, escolheria seguramente este festival, a maior mostra de teatro nacional, com espectáculos para todos os tipos de público e faixas etárias. Touches and Connections foi iniciado, curiosamente, também há oito anos (2005 foi um ano fértil na criação de novos festivais). Ai pode ver-se uma grande variedade de espectáculos oriundos de todo o país (e alguns recuperados de outros festivais, tais como o Nová Dráma).

$\mathrm{Na}$ edição deste ano, e para selecionar alguns dos mais interessante e controversos, foi apresentado Psota (Pobreza) da companhia Pôtoň, oriunda de uma pequena aldeia - e pobre - do sul do país. Pobreza parte de um trabalho de campo realizado numa outra aldeia pobre e apresenta personagens que vivem nas margens da sociedade, muitas vezes em situações degradantes. 0 cenário, feito com dezenas de frigorificos velhos que representavam as divisões pequenas e estreitas de uma casa, recebeu o prestigiante prémio Board, atribuído aos melhores trabalhos teatrais realizados durante a temporada, no Nitra Theatre Festival, em Setembro. Outro nomeado (e merecedor do prémio para melhores figurinos) foi o espectáculo Illuminárium, da (já mencionada) companhia P.A.T. de Sláva Daubnerová, que colaborou, desta vez, com um conhecido bailarino, Emil Leeger. Illuminárium é uma fascinante viagem pela história, desde o período de um big boom de magia de mesa, e de outras formas de ilusionismo, até à história de Victor Ponrepo, o primeiro 


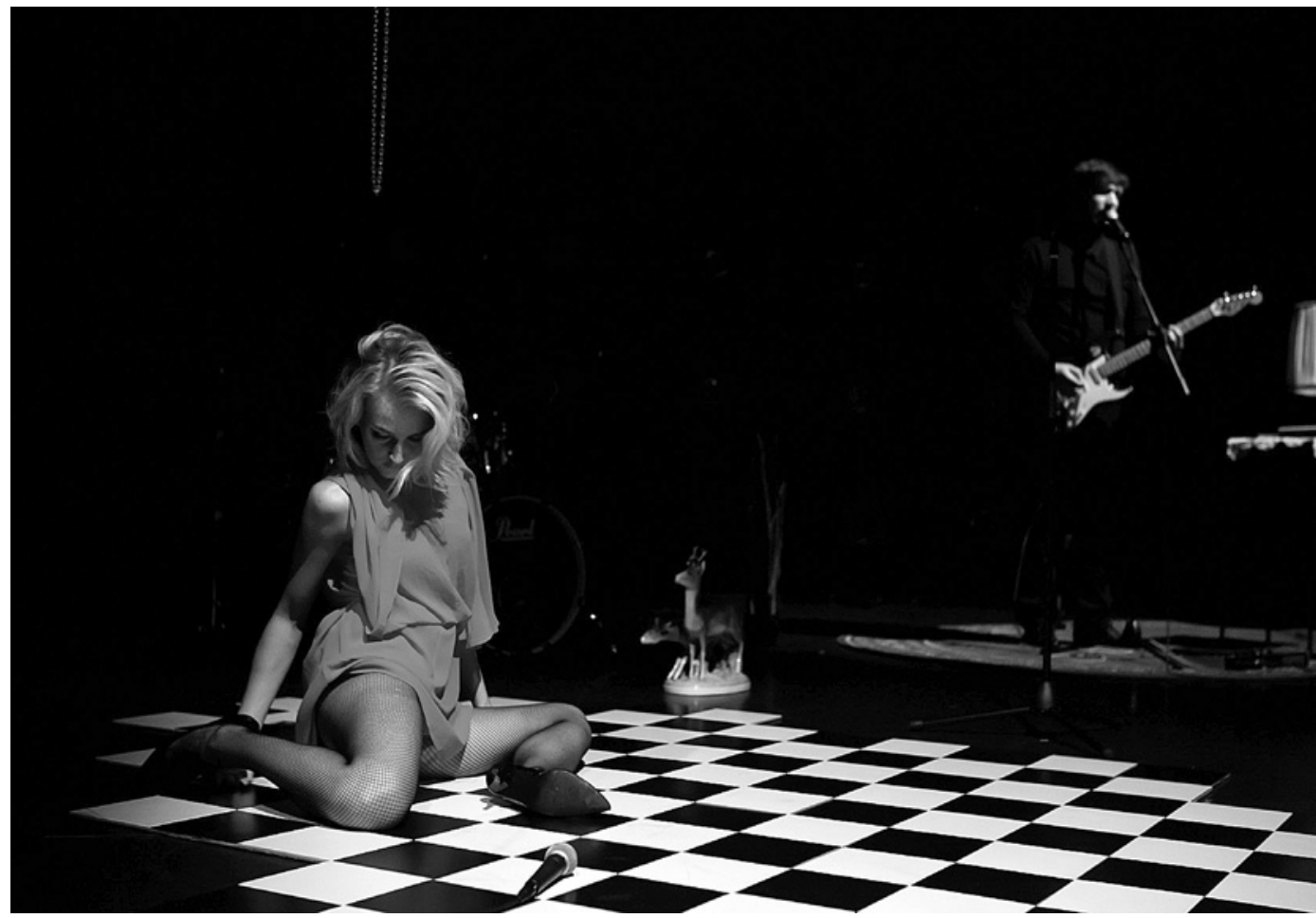

Some Disordered Interio Geometries,

proprietário de um cinema na República Checa, no principio do século XX.

Relevantes são também os programas de apoio de ambos os festivais. Ao passo que o Nová Dráma tem vários seminários e oficinas para jovens críticos, Touches and Connections é conhecido pelas suas manhãs criticas, em que criadores e críticos se encontram para discutir em conjunto os espectáculos do dia anterior. Nesse festival, também foram lidos os textos vencedores do projecto europeu Platform 11+. E, encimando tudo isto, uma conferência sobre teatro no âmbito dos trabalhos da Associação Internacional de Críticos de Teatro (AICT/IATC). E, claro, se o espectador se sentir fatigado de tantos espectáculos e de tantas sessões teóricas, pode também ir procurar o seu descanso nos vários concertos e festas.

Mas e se este mesmo espectador estiver interessado num teatro de natureza mais específica, provavelmente mais alternativo? Quer o Nová Dráma quer Touches and Connections são festivais para um público genérico, misturando espectáculos de várias tipologias. Mas tal não é o caso do festival Arteterapia. 0 nome pode ser enganador: pode sugerir uma qualquer aplicação terapêutica do teatro, mas não é o caso. Arteterapia é, por um lado, um festival aberto a todos aqueles que gostam de um teatro socialmente activo, e é, por outro, essencialmente dedicado a práticas de teatro comunitário. Apesar de existir desde 2002, esta é "somente" a sua quinta edição, com o título FreeDOM, e ocorreu em Junho. "Dom" significa casa ou, em sentido figurado, lar. Arteterapia é, assim, um lugar acolhedor e amigável onde, durante uns dias, se pode questionar o conceito de casa/lar. No contexto do festival, foi desenvolvido um projecto especial intitulado "Casa de resistência", uma exposição que reunia vários géneros e formatos, onde os artistas exprimiam o seu descontentamento sobre a situação política nacional e internacional. Assim, protestavam contra os últimos escândalos financeiros e políticos que se registaram na
Eslováquia, mas também contra os incompetentes governantes das estruturas europeias em geral.

Os espectáculos apresentados no programa principal estavam, de alguma maneira, subordinados ao tema "Casa". Assim, por exemplo, os actores do Theatre from Passage, o único teatro que trabalha continuadamente com deficientes, mostraram-nos, com Hamlet a syn (Hamlet e o filho), que o teatro é realmente a sua segunda casa. Também tivemos a oportunidade de tentar perceber o que é não ter casa, no espectáculo Paso e paso (The jouney of an injured warrior) (A viagem de um guerreiro ferido). Uma vez que Arteterapia é também um festival internacional, Jing Lu trouxe a história de um imigrante chinês que vive na República Checa. No perturbante "one-woman-show" Solo for Lu (Um solo para Lu), eram apresentados fragmentos da sua própria vida, que é a vida de alguém que não se consegue sentir em casa nem no seu próprio pais (porque a sua familia é, entre outras coisas, perseguida por ter mais do que uma filha), nem em lado nenhum. 0 programa deste ano incluiu também o espectáculo de clown, Funky Pudding, onde duas personagens, os semabrigo Marylin e Big Mac que vivem num caixote do lixo, numa série de sketches cómicos, lidam com o tema do consumismo e do desperdicio.

Contudo, se eu estivesse à procura de espectáculos de natureza mais experimental, de teatro-físico ou de cruzamento de linguagens, a opção perfeita seria o KioSK, um dos mais jovens festivais. Decorre no Verão, normalmente na segunda metade de Julho, quando os teatros de reportório estão, normalmente, de férias. Originalmente organizado pelo Instituto Eslovaco de Teatro, em Bratislava, é, desde há cinco anos, uma actividade da responsabilidade do centro cultural Žilina-Záriečie Station, uma estação ferroviária renovada onde a arte contemporânea tem lugar cativo. A programação do KioSK - subintitulado "um festival para um espectador corajoso" - dá preferência a espectáculos que testem os limites da 
representação tradicional. Apesar de se constituir como uma mostra do mais relevante teatro, dança e música (e até cinema) independentes, os artistas envolvidos trabalham normalmente no estrangeiro. Na edição de 2012, entre os convidados estiveram o bailarino Matej Matejka e os seus alunos do Studio Matejka, dependentes do Instituto Grotowski, em Wroclaw. No espectáculo Všetko čo si nepamätám z našich stretnutí (Tudo aquilo que não me lembro das nossas reuniões) e numa série de pequenos filmes realizados por Adam Hanuljak, provaram a sua capacidade de enorme concentração em dificeis coreografias. Um membro do Bodytalker Ensemble, de Bruxelas, o bailarino Peter Šavel criou com Peter Dobák um solo sobre estereótipos sociais intitulado Could we $f$ lie together? (Podiamos f... e deitarmo-nos / mentir / voar juntos?) e Much More Than Nothing (Muito mais do que nada), um espectáculo com que parodiava a figura típica do encenador-coreógrafo que dirige à bruta os seus intérpretes e as fúteis competições de dança. Zuzana Burianová, no filme Kto z koho? (Quem ganha a quem?), criou uma coreografia para dois dançarinos profissionais baseada nos movimentos quotidianos de um professor de piano e de um professor de quimica, combinando e comparando movimentos naturais e artificiais em sequências de vídeo paralelas.

KioSK é uma das raras plataformas onde se presta uma particular atenção à iluminação e ao trabalho do desenho de luz. Durante o festival há várias instalações de luz em exibição, é atribuído o prémio Poučn para o melhor trabalho de luz num espectáculo e os participantes da oficina "Desenho de luz: do conceito à concretização" apresentaram os seus trabalhos em três exercicios. As oficinas de dança são já uma tradição neste festival: este ano com o título "A complexidade do performer" teve dois monitores: três dias com Jaro Viňarský, seguidos de outros três dias com Matej Matejka. 0 programa do festival é complementado com mercados de produtos caseiros e artesanato, projecções de filmes, concertos, festas e, claro, muitas conversas entre criadores e espectadores. Para os espectadores que não se querem arriscar a perder os primeiros espectáculos da manhã, há espaços para acampar. Por tudo isto, KioSK é um festival que deve ser experienciado em toda a sua complexidade e vale bem a pena ser corajoso para o visitar.

Em suma, para um espectador entusiasta, não há razão para se aborrecer. Mas a escolha dependerá, em última análise, das datas. Para o final do Verão ainda poderia recomendar um festival de humor e de teatro satírico, com mais de trinta anos de existência, o Kremnické Gagy (Gargalhadas de Kremnica). Ou o festival de teatro de amadores que o Divadelná Žatva (Colheita de palco), organiza há mais de noventa anos, em Setembro. Ou o prestigiado festival internacional Divadelná Nitra (Nitra Teatral) com mais de vinte anos. Se eu fosse uma espectadora de teatro de férias na Eslováquia, saberia o que fazer. Que pena eu não ser uma espectadora de teatro de férias na Eslováquia. Mas o leitor desta revista de teatro portuguesa pode vir a ser.

Tradução de Rui Pina Coelho 